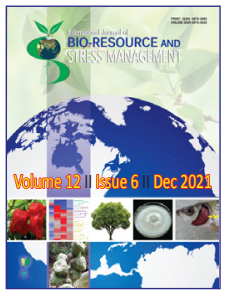

\title{
Essential Oils: An Effective Therapeutic Strategy against SARS-CoV-2
}

\author{
Santwana Palai ${ }^{1}$ and Shyam Sundar Kesh ${ }^{2 *}$
}

${ }^{1}$ Dept. of Veterinary Pharmacology \& Toxicology, College of Veterinary Science and Animal Husbandry, OUAT, Bhubaneswar, Odisha (751 003) India

${ }^{2}$ Dept. of Veterinary Clinical Complex (Veterinary Biochemistry), F/O-VAS, West Bengal University of Animal and Fishery Sciences, Kolkata, West Bengal (700 037) India

\section{ก \\ Open Access \\ Corresponding Author \\ Shyam Sundar Kesh \\ e-mail: keshvbc@gmail.com}

Citation: Palai and Kesh, 2021. Essential Oils: An Effective Therapeutic Strategy against SARS-CoV-2. International Journal of Bio-resource and Stress Management 2021, 12(6), 719-724. HTTPS://DOI. ORG/10.23910/1.2021.2656a.

Copyright: (c) 2021 Palai and Kesh. This is an open access article that permits unrestricted use, distribution and reproduction in any medium after the author(s) and source are credited.

Data Availability Statement: Legal restrictions are imposed on the public sharing of raw data. However, authors have full right to transfer or share the data in raw form upon request subject to either meeting the conditions of the original consents and the original research study. Further, access of data needs to meet whether the user complies with the ethical and legal obligations as data controllers to allow for secondary use of the data outside of the original study.

Conflict of interests: The authors have declared that no conflict of interest exists.

\begin{abstract}
Thousands of individuals have perished as a result of Covid-19 and it has turned into a global problem. The novel coronavirus 2019 (nCoV-2019), also known as Severe Acute Respiratory Syndrome Coronavirus 2 (SARS-CoV-2), has spread rapidly following its discovery in Wuhan patients with acute pneumonia in China. No medication or vaccine are available to treat human coronavirus infection successfully. The alternative therapies and cures are not are effective or authorised to treat Corona virus. Treatments are primarily supportive because no particular pandemic cure has been licenced. New interventions will most likely take months to years to mature. Using antiviral medicinal herbs as an auxiliary or supportive therapy seems to be a viable alternative. The essential oils of medicinal plants have antiviral and immunomodulatory effects. Being rich in antioxidants, essential oils can be used to develop new antiviral remedies. Such beneficial essential oils are being evaluated and exploited for its potent therapeutic use against many viruses. These natural compounds bestow antiviral actions by disrupting the viral life cycle during viral entry, assembly, replication, discharge and virus-specific host targets. This study highlights the essential oils derived from medicinal and aromatic plants with in vitro and in vivo antiviral effects. Essential oils having known pharmacokinetic and pharmacodynamic properties can be repurposed as a strategy against deadly SARS-CoV-2 infection. These essential oils of herbal plants can be an effective therapeutic strategy against SARS-CoV-2 when used along with conventional antiviral medicines.
\end{abstract}

Keywords: Aromatic plants, COVID-19, medicinal plants, SARS-CoV-2

\section{Introduction}

Several instances of unexplained pneumonia were reported in the Chinese province of Hubei around December 2019. The virus was quickly recognised as fitting to the Coronaviridae family, which is associated with the virus causing severe acute respiratory syndrome (SARS). The virus causing COVID-19 is called as SARS-CoV-2 (severe acute respiratory coronavirus syndrome 2) (Jamalipour Soufi and Iravani, 2021). On January $30^{\text {th }}$, the WHO declared the sickness a global public health emergency, and on March $11^{\text {th }}, 2020$, it was declared a pandemic. Vaccines, interferon treatments, and small-molecule medicines are potential possibilities for managing or preventing development of 2019-nCoV infections but currently no particular antiviral therapy or vaccination are effective against it. The available antiviral medications usually result in the development

Article History

RECEIVED on $05^{\text {th }}$ October 2021 RECEIVED in revised form on $10^{\text {th }}$ December 2021 ACCEPTED in final form on $27^{\text {th }}$ December 2021 
of viral resistance and side effects. More research and clinical trials are required to create effective medicines or potential vaccines against SARS-CoV-2. Also, the relevant validation of medicine is a lengthy procedure.

The enveloped viruses are protected by a lipid membrane, which allows them to better adapt to immunity. As essential oils are hydrophobic, they act on the lipids in bacterial and mitochondrial cell membranes, making them more permeable by disrupting cell structures and death (Chouhan et al., 2017). So, essential oils can be tried as broad-spectrum remedies against SARS-CoV-2 epidemic and widespread crises (Khadija, 2021).

Essential oils are a complex combination of volatile phytochemicals that include sesquiterpenes, monoterpenes and phenylpropanoids. Essential oils have long been known for their antioxidant and antiviral effects. These essential oils are effective against influenza, AIDS, yellow fever, and avian influenza viruses, etc. (Asif et al., 2020). Essential oils from Leptospermum scoparium, Illicium verum, Matricaria recutita and Melaleuca alternifolia, were used to suppress acyclovir-sensitive and resistant HSV stains, demonstrating their antiviral activity (Reichling et al., 2009). Rosamarinus officinalis, Lavender officinalis, Cinnamomum camphora, Mellaleuca alternifolia, Citrus bergamia, Eucalyptus globulus, Citrus limon, Mentha piperita, Foeniculum vulgare etc. possess essential oils with anti-influenza properties (Figure 1). These vapourised essential oils benefit patients suffering from influenza (Asif et al., 2020). This article summarises such potential essential oils which can extend benefits in respiratory infections of COVID-19. It will aid researchers and pharmaceutical developers in establishing of COVID-19 controlling drugs either singly or with existing therapeutic regimen against SARS-CoV-2.

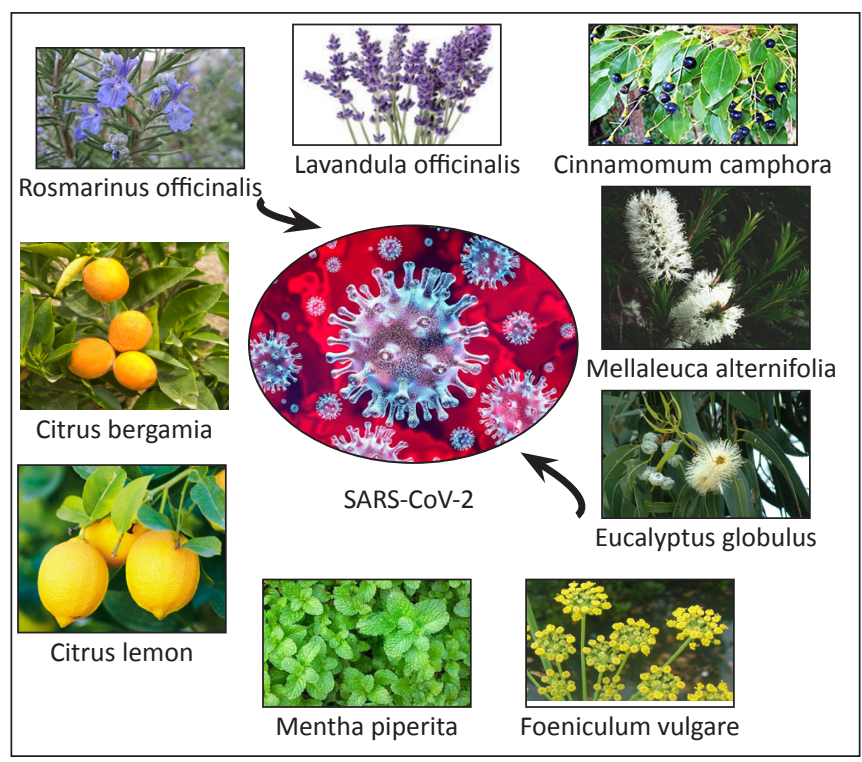

Figure 1: Plants having essential oils

\section{Covid-19 Structure and Pathophysiology}

COVID-19 is produced by the SARS CoV-2 virus linked to the
SARS-CoV-1 virus causing the 2003 SARS. Nonetheless, both of these disorders have different symptoms and develop in their own way. Both viruses have a similar shape, with a spherical protein capsule containing a ribonucleic acid strip and a capsule encased in spikes completely (Ortiz-Prado et al., 2020). These spikes bind to the cell surface receptors lining the human lung. Similar type of receptor allows the virus to enter the cell. The virus after access to the cell, controls the cell's reproductive process to generate more virus replicas till it becomes infectious and breaks forth from the cell confinement (Abd El-Aziz and Stockand, 2020).

SARS was less infectious than COVID-19, yet it killed more people. SARS-CoV-2 (Covid-19 virus) is genetically similar to SARS-CoV-1 up to $90 \%$. Because their identical genetic makeup, the chemicals that blocked the reproduction of SARS-CoV-1 might be used against Covid-19 (Ortiz-Prado et al., 2020). Identifying medications with high target specificity or exposing current therapies can be used to repurpose them for COVID-19 treatment (Liu et al., 2020). Papain-like protease (PLpro) and 3C-like protease (3CLpro) are the viral proteases that cleave viral peptides into functional units for virus replication and packaging inside host cells. Drugs targeting these proteases in other viruses, can be tested against SARS-CoV-2 too (Sheahan et al., 2020). The primary viral protease for polyproteins production translated from viral RNA, is a popular pharmaceutical target among SARSCoV-1 and 2. It evolved into an efficient SARS-CoV-2Mpro inhibitor, and revealed a strong lung tropism and suitability for inhalation delivery (Jamalipour Soufi and Iravani, 2021). The interaction of viral S protein with its receptor ACE2 on host cells and the resulting viral endocytosis into the cells can serve as therapeutic objective. Any virus-host cell fusion inhibitor that limits viral entrance into cells of the host acting against the flu virus can be tried also for SARS-CoV-2 treatment (Li and Clercq, 2020).

\section{Essential Oil has a Therapeutic Strategy against SARS- CoV-2}

The antiviral potential of natural products is understudied particularly against RNA viruses that cause endemic and pandemic illnesses. The natural drug discovery from nature and its development is ultimately beneficial to human civilization, the planet and environment (Christy et al., 2020). Antiviral formulations that include various phytochemicals working against Cov-1 specifically targeting molecular targets may also work against Cov-2. In the absence of an acceptable or internationally recognised medication for SARS and Covid-19, these bioactive have been tried to reduce deadly viruses' infections. Owing to their identical genetic makeup, the chemicals that can block the reproduction of SARS-CoV-1 might be useful against Covid-19. Volatile oil components of eucalyptus oil, rosemary oil, tea tree oil, lavender oil, bergamot oil, lemon oil, etc. have antiviral effects on the basis of their chemistry (Table 1). As these essential oils are lipophilic, they may disrupt the SARS-CoV-2 membrane, 
Table 1: Structure and source of essential oils as therapeutic agents against SARS-CoV-2

SI. Name of the Structure Source Reference

No. essential oil

1. 1,8 -cineole

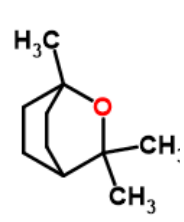

Laurus nobilis, Rosmarinus officinalis

Tshibangu et al., 2020

2. Alpha-pinene

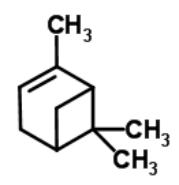

Eucalyptus globulus, Corymbia citrodora, Panikar et al., 2021. Rosmarinus officinalis

3. $\beta$-pinene

4. Linalool

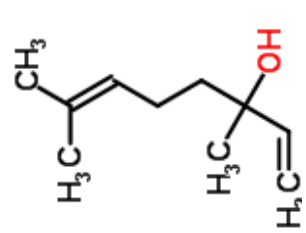

5. Alpha-terpineol<smiles>CC1=CCC(C(C)(C)O)CC1</smiles>

6. Citronellol<smiles>CC(C)=CCCC(C)CCO</smiles>

7. Viridiflorol

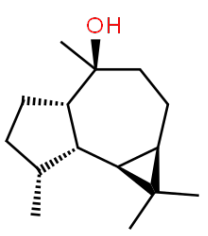

8. Bergamot

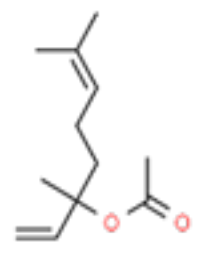

9. d-Limonene<smiles>C=C(C)C1CC=C(C)CC1</smiles>

Satureja thymbra, Rosmarinus officinalis

Satureja. Thymbra, Lavandula officinalis

Corymbia citrodora, Eucalyptus globulus

Corymbia citrodora

Melaleuca quinquinervia

Citrus bergamia, Citrus limon

Eucalyptus globulus, Citrus limon
Battistini et al., 2019

Abou Baker et al., 2021

Panikar et al., 2021.

Panikar et al., 2021.

Padovan et al., 2010

Panyod et al., 2020

Panikar et al., 2021. Meeran et al., 2020 


\begin{tabular}{|c|c|c|c|c|}
\hline $\begin{array}{l}\text { SI. } \\
\text { No. }\end{array}$ & $\begin{array}{l}\text { Name of the } \\
\text { essential oil }\end{array}$ & Structure & Source & Reference \\
\hline 10. & Eucalyptol & & Eucalyptus globulus, Corymbia citrodora & Panikar et al., 2021. \\
\hline 11. & Cajeput & - & Melaleuca leucadendron & Kacaniova et al., 2020. \\
\hline 12. & Thymol & & Salvia officinalis & Tshibangu et al., 2020 \\
\hline 13. & o-Cymene & & Eucalyptus globulus, Corymbia citrodora & Panikar et al., 2021. \\
\hline 14. & Eugenol & & Laurus nobilis & Jahan et al., 2021 \\
\hline 15. & Carvacrol & & Satureja thymbra oil & Tshibangu et al., 2020 \\
\hline
\end{tabular}

limiting viral replication by acting individually or synergistically against viral targets (Jahan et al., 2021). Essential oils have long been recognised to have antioxidant, antiviral, antiinflammatory, and immunomodulatory effects. So, they may also have anti-SARS-CoV-2 action (Asif et al., 2020).

\subsection{Rosemary oil (Rosmarinus officinalis)}

Due to the potent antiviral action of its primary chemical components such as 1, 8-cineole, alpha-pinene, beta-pinene, and Terpineol against SARS-CoV-1, it may be effective in COVID-19. It can help with mental apathy, the immune system modulation and breathing. Rosemary 1, 8-cineole was the most efficient essential oil at lowering virus titers and demonstrating antiviral action (Battistini et al., 2019).

\subsection{Lavender oil (Lavandula officinalis)}

It can assist with anxiety, stress hormone regulation, and a variety of respiratory issues. Linalool and linalyl acetate were the two main ingredients of lavender oil. It has anti- inflammatory, antioxidant, and antiviral properties (Abou Baker et al., 2021).

\subsection{Ravintsara oil (Cinnamomum camphora)}

It possesses antiviral activity against a variety of viruses and may be able to inhibit Covid-19. It possesses various chemical components that have the capability to halt viral multiplication. The oil is antiviral, antioxidant, antiinflammatory and can be effective antiviral medicines for viral infections of the respiratory system, making them a promising contender against coronavirus (Malabadi et al., 2021).

\subsection{Tea tree oil (Mellaleuca alternifolia)}

It can treat common cold, cold sores and influenza. The medicinal components of tea tree oil exhibit synergistic antiviral effects, with potential effectiveness against Covid-19. The major active ingredients were terpinolene, viridiflorol and alfa-terpineol. Its active components have distinct effects on diverse points of the influenza virus's replication cycle. It may 
stop viruses from uncoating by interfering with the acidity of the intralysosomal compartment (Garozzo et al., 2011).

\subsection{Bergamot oil (Citrus bergamia)}

Citronellal, the primary active component, has been demonstrated to be antiviral. It has the potential to suppress the SARS-CoV-2 virus as it has anti-influenza properties (Panyod et al., 2020).

\subsection{Lemon oil (Citrus limon)}

It is capable of preventing the reproduction of influenza virus. d-Limonene, a natural dietary terpene targets viral protein. Inflammatory mediators like cytokines, chemokines, adhesion molecules, prostanoids, and eicosanoids are blocked, and several signalling pathways are regulated. The pathophysiology of COVID-19, which involves infection and inflammation, can be slowed down by limonene's immunomodulatory, anti-inflammatory, and antiviral properties, decreasing the disease's severity and progression (Meeran et al., 2020).

\subsection{Eucalyptus oil (Eucalyptus globulus)}

Its' essential oils have antiviral properties. Patients with moderate and uncomplicated coronavirus infections may benefit from eucalyptol as an integrative treatment for symptom relief (Valussi et al., 2021)

\subsection{Peppermint oil (Mentha piperita)}

It possesses antibacterial and antiviral which inhibited the production of TNF-, IL-6, NO, and PGE2 and was effective against RSV. The existence of a large number of phenolic compounds resulted in significant antioxidant action ( $\mathrm{Li}$ et al., 2017).

\subsection{Fennel oil (Foeniculum vulgare)}

It has strong antiviral properties. Bitter fennel fruit oil is an expectorant for coughs induced by a cold. The major components of the oil are fenchone and trans-anethole (Stefanidesova et al., 2019).

This revealed that naturally occurring essential oils are found in antiviral aromatic plants. These constituents of essential oils can also act as therapeutic agents against SARS-CoV-2 (Table 1). Other important constituents include thymol, o-cymene, eugenol, carvacrol, etc.

Essential oils were efficient against COVID-19 because to their varied antiviral characteristics. Essential oils substantially reduced ACE2 expression in epithelial cells due to these chemical components and prevent of the SARS-CoV-2/ COVID-19 invasion into the human body (Senthil Kumar et al., 2020). Due to their lipophilic nature, essential oils can intercalate into the lipid bilayer layer of the viral envelope. Membrane fluidity is changed as a result, and membranes are ripped at higher concentrations. Essential oil compounds interfere with life cycle of virus like viral entrance, assembly, replication, and release aiming host-virus interactions like as hydrogen bonds and van der Waals interactions (Tshibangu et al., 2020).

\section{Future Perspective}

Further in vitro and in vivo research is desirable to fully comprehend the essential oils and their components' potential against SARS-CoV-2. Encapsulation of essential oils through a nanoprecipitation technique may help in targeted essential oils release to specific locations in body. Molecular docking investigations and pharmacoinformatic of some naturally occurring essential oils chemo-types against SARSCoV-2 proteases are required to discover possible inhibitors. Clinical studies will be needed to confirm the essential oils' effectiveness against Covid-19 and the development of anti-COVID-19 alternative based-method using reverse pharmacology approach.

\section{Conclusion}

The aromatic plant species yielding essential oil display antiviral bioactivities which justifies their use against SARSCoV-2. Antiviral activities include direct effects on free viruses, the inhibition of important viral enzymes and decrease in processes of virus attachment, penetration, intracellular reproduction, and escape from host cells. Inhaling essential oils like rosemary, lavender, tea tree, bergamot, peppermint, cinnamon, eucalyptus, fennel, lemon, etc. using a simple essential oils diffuser or nebulizer can extend relief in Covid-19 illness.

\section{Reference}

Abd El-Aziz, T.M., Stockand, J.D., 2020. Recent progress and challenges in drug development against COVID-19 coronavirus (SARS-CoV-2)-an update on the status. Infection, Genetics and Evolution 83, 104327

Abou Baker, D.H., Amarowicz, R., Kandeil, A., Ali, M.A., Ibrahim, E.A., 2021. Antiviral activity of Lavandula angustifolia L. and Salvia officinalis L. essential oils against avian influenza H5N1 virus. Journal of Agriculture and Food Research 4, 100135.

Asif, M., Saleem, M., Saadullah, M., Yaseen, H.S., Al Zarzour, R., 2020. COVID-19 and therapy with essential oils having antiviral, anti-inflammatory, and immunomodulatory properties. Inflammopharmacology, 1-9.

Battistini, R., Rossini, I., Ercolini, C., Goria, M., Callipo, M.R., Maurella, C., Pavoni, E., Serracca, L., 2019. Antiviral activity of essential oils against hepatitis $A$ virus in soft fruits. Food and environmental virology 11(1), 90-95.

Chouhan, S., Sharma, K., Guleria, S., 2017. Antimicrobial activity of some essential oils-present status and future perspectives. Medicines (Basel, Switzerland) 4(3), 58. https://doi.org/10.3390/medicines4030058.

Christy, M.P., Uekusa, Y., Gerwick, L., Gerwick, W.H., 2020. Natural products with potential to treat RNA virus pathogens including SARS-CoV-2. Journal of Natural Products 84(1), 161-182.

Garozzo, A., Timpanaro, R., Stivala, A., Bisignano, G., Castro, 
A., 2011. Activity of Melaleuca alternifolia (tea tree) oil on Influenza virus A/PR/8: Study on the mechanism of action. Antiviral research, 89(1), 83-88.

Jahan, R., Paul, A. K., Jannat, K., Rahmatullah, M., 2021. Plant Essential Oils: Possible COVID-19 Therapeutics. Natural Product Communications 16(2), 1934578X21996149.

Jamalipour Soufi, G., Iravani, S., 2021. Potential inhibitors of SARS-CoV-2: recent advances. Journal of Drug Targeting 29(4), 349-364.

Kacaniova, M., Terentjeva, M., Kunova, S., Rovna, K., Ziarovska, J., Borotova, P., Valkova, V., Galovicova, L., 2020. Antibiofilm Activity of Cajeput (Melaleuca Leucadendron) Eessential oil against Stenotrophomonas maltophilia. Scientific Papers: Animal Science \& Biotechnologies/Lucrari Stiintifice: Zootehnie si Biotehnologii 53(2).

Khadija, B.A.R.Y., 2021. Essential oils a challenge against Covid-19. Journal of Analytical Sciences and Applied Biotechnology 3(1), 1-3.

Li, G., De Clercq, E., 2020. Therapeutic options for the 2019 novel coronavirus (2019-nCoV). Nature reviews Drug discovery 19(3), 149-150.

Li, Y., Liu, Y., Ma, A., Bao, Y., Wang, M., Sun, Z., 2017. In vitro antiviral, anti-inflammatory, and antioxidant activities of the ethanol extract of Mentha piperita L. Food science and biotechnology 26(6), 1675-1683. https://doi. org/10.1007/s10068-017-0217-9

Liu, F., Xu, A., Zhang, Y., Xuan, W., Yan, T., Pan, K., Yu, W., Zhang, J., 2020. Patients of COVID-19 may benefit from sustained lopinavir-combined regimen and the increase of eosinophil may predict the outcome of COVID-19 progression. International Journal of Infectious Diseases 95, 183-191.

Malabadi, R.B., Kolkar, K.P., Meti, N.T., Chalannavar, R.K., 2021. Role of botanical essential oils as a therapy for controlling coronavirus (SARS-CoV-2) disease (Covid-19). International Journal of Research and Scientific Innovation 8(4), 105-118.

Meeran, M.N., Arunachalam, S., Javed, H., Sharma, C., Hashiesh, H.M., Goyal, S.N., Jha, N.K., Ojha, S., 2020. Can limonene be a possible candidate for evaluation as an agent or adjuvant against infection, immunity, and inflammation in COVID-19?. Heliyon, e05703.

Ortiz-Prado, E., Simbana-Rivera, K., Gomez-Barreno, L., RubioNeira, M., Guaman, L.P., Kyriakidis, N.C., Muslin, C., Jaramillo, A.M.G., Barba-Ostria, C., Cevallos-Robalino, D., Sanches-SanMiguel, H., 2020. Clinical, molecular, and epidemiological characterization of the SARS-CoV-2 virus and the Coronavirus Disease 2019 (COVID-19), a comprehensive literature review. Diagnostic Microbiology and Infectious Disease 98(1), 115094.
Padovan, A., Keszei, A., Kollner, T.G., Degenhardt, J., Foley, W.J., 2010. The molecular basis of host plant selection in Melaleuca quinquenervia by a successful biological control agent. Phytochemistry 71(11-12), 1237-1244.

Panikar, S., Shoba, G., Arun, M., Sahayarayan, J.J., Nanthini, A.U.R., Chinnathambi, A., Alharbi, S.A., Nasif, O., Kim, H.J., 2021. Essential oils as an effective alternative for the treatment of COVID-19: Molecular interaction analysis of protease (Mpro) with pharmacokinetics and toxicological properties. Journal of Infection and Public Health 14(5), 601-610.

Panyod, S., Ho, C.T., Sheen, L.Y., 2020. Dietary therapy and herbal medicine for COVID-19 prevention: A review and perspective. Journal of traditional and complementary medicine 10(4), 420-427.

Reichling, J., Schnitzler, P., Suschke, U., Saller, R., 2009. Essential oils of aromatic plants with antibacterial, antifungal, antiviral, and cytotoxic properties-an overview. Complementary Medicine Research 16(2), 79-90.

Senthil Kumar, K.J., Gokila Vani, M., Wang, C.S., Chen, C.C., Chen, Y.C., Lu, L.P., Huang, C.H., Lai, C.S., Wang, S.Y., 2020. Geranium and lemon essential oils and their active compounds downregulate angiotensin-converting enzyme 2 (ACE2), a SARS-CoV-2 spike receptor-binding domain, in epithelial cells. Plants 9(6), 770.

Sheahan, T.P., Sims, A.C., Leist, S.R., Schafer, A., Won, J., Brown, A.J., Montgomery, S.A., Hogg, A., Babusis, D., Clarke, M.O., Spahn, J.E., 2020.Comparative therapeutic efficacy of remdesivir and combination lopinavir, ritonavir, and interferon beta against MERS-CoV. Nature communications 11(1), 1-14.

Stefanidesova, K., Spitalska, E., Csicsay, F., Friedlanderova, V., Saner, A., Skultety, L., 2019. Evaluation of the possible use of genus Mentha derived essential oils in the prevention of SENLAT syndrome caused by Rickettsia slovaca. Journal of Ethnopharmacology 232, 55-61.

Tshibangu, D.S.T., Matondo, A., Lengbiye, E.M., Inkoto, C.L., Ngoyi, E.M., Kabengele, C.N., Bongo, G.N., Gbolo, B.Z., Kilembe, J.T., Mwanangombo, D.T., Mbadiko, C.M., Mihigo, S.O., Tshilanda, D.D., Ngbolua, K.T.N., Mpiana, P.T., 2020. Possible effect of aromatic plants and essential oils against COVID-19: Review of their antiviral activity. Journal of Complementary and Alternative Medical Research 11(1), 10-22. https://doi. org/10.9734/jocamr/2020/v11i130175).

Valussi, M., Antonelli, M., Donelli, D., Firenzuoli, F., 2021. Appropriate use of essential oils and their components in the management of upper respiratory tract symptoms in patients with COVID-19. Journal of Herbal Medicine 100451. 